\title{
OPINION
}

... BDA meetings are incredibly varied, ranging from the slumbering small group

of die hards ... to an almost riotously enthusiastic band of professionals ...

\section{The 'real' BDA}

At the BDA Conference in Bournemouth this year one of the sessions involved BDA Branch and Section secretaries, who were invited to look at the future for BDA branches and sections, and also consider ways of working together to help achieve the objectives of the BDA as a whole. The session was both interesting and enlightening, especially when people began to question the old established way of looking at things and considered methods of changing the format of branch and section meetings to meet the changing needs of the profession.

The first subject on the agenda at the meeting was the most obvious one, and paradoxically perhaps the most difficult. They had to identify the aims and objectives of branches and sections to answer the question 'Are they still valid today?' Naturally there was an element of bias in the discussion, as people who take the post of branch or section secretary are obviously more likely to support the concept, otherwise it is unlikely they would have been elected in the first place. That aside, the discussion as to the need was refreshingly honest and questioning.

Not surprisingly different secretaries had different experiences, and identified different needs for their particular membership. Everyone agreed that education was an important part of the role for branches and sections, especially since the introduction of mandatory $\mathrm{CPD}$, and one person made the astonishing comment that BDA meetings was the only (my emphasis) place where dentists could obtain postgraduate education. I wonder what the postgraduate dental deans and the dental schools would think of that comment! Most people also thought that the social aspect of the meetings was a very important role, especially for single-handed practitioners who had little opportunity otherwise to meet their colleagues.

A few of the myths about BDA meetings were also shattered during the session, which was welcome. One of these was the common perception that BDA meetings are just for white middle-aged middle class males. This is not so, as a high proportion of secretaries at the meeting were female, and young. In fact two people present were vocational dental practitioners who were enthusiastically getting to grips with providing meetings for their area. While it remains true that some sections are still monopolised by the traditional older male dentists (and thus mainly composed of similar people) there is a growing healthy trend towards diversity. Of course many dentists never appreciate this fact as they tend to visit the same local section for most of their working lives, never experiencing the rich variety around the country. As someone who has been to many different BDA meetings over the years I can confirm that BDA meetings are incredibly varied, ranging from the slumbering small group of die-hards who hardly seem to acknowledge newcomers (and speakers as well, sad to say) to an almost riotously enthusiastic band of professionals of all ages and gender who enjoy the opportunity to meet and share all things dental. As a speaker you just never know what you are going to find when you accept an invitation to speak.

This variety is important, but the essential message for all BDA sections and branches is that they must embrace the opportunity to meet the needs of their local members if they are to be effective. Small social clubs may have worked in the past, but the changing demographics of the profession are forcing us to look hard at what we need for the future if we are to fulfil the objectives of the BDA. Dentistry can be a lonely profession, and the opportunity to meet and share with colleagues is a vital part of professional development.

At the end of the day, though, the ultimate question has to be 'What if we got rid of them?' Would it matter?

While some might agree that eliminating sections and branches is the best way forward, is it really right for the future? The strength of the BDA lies in the membership, not at Wimpole Street. People often tell me (in my role as editor) that the BDA has got this or that wrong, or is doing all the wrong things again, as if the BDA were a separate body from them. My reply has to be 'But you are the BDA as well' because that is the truth. Each member represents our association, and each of us has responsibility for the actions of the whole. If this is true, then branches and sections are the real BDA after all. Now that's an interesting thought.

Mike Grace, Editor m.grace@bda.org doi: 10.1038/sj.bdj.4811342 